\title{
SKETCH-UP
}

\section{Volatile Siberian trap eruptions}

Nat. Geosci. https://doi.org/10.1038/s41561-018-0215-4 (2018)
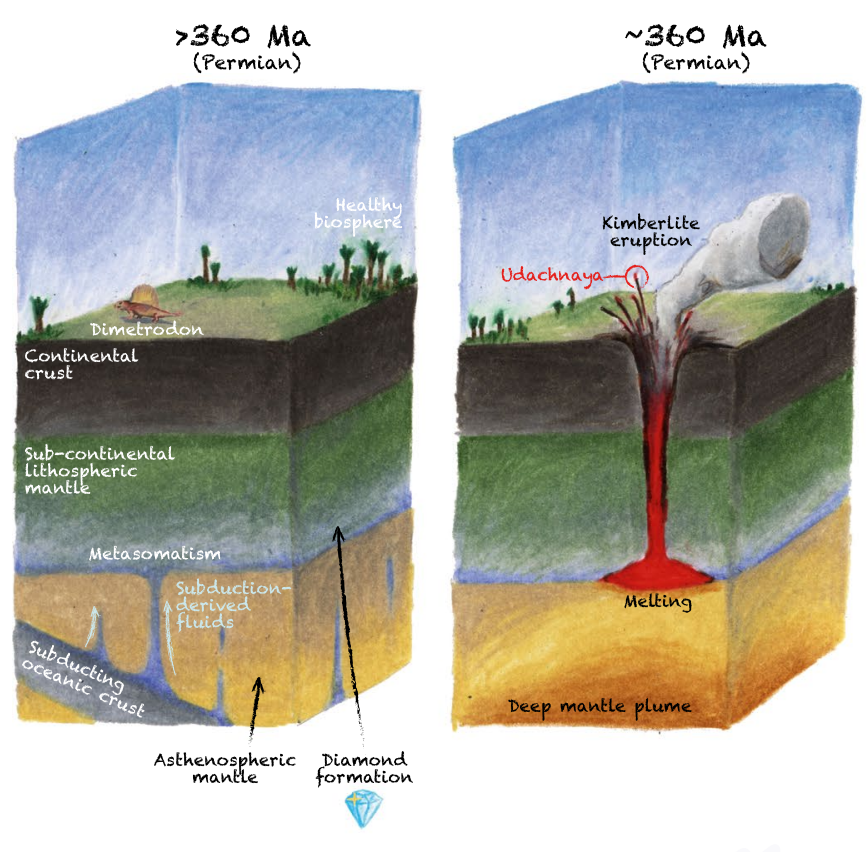

Broadley et al. present geochemical analyses of mantle xenoliths emplaced before and after the eruption of the siberian flood basalts that have been linked to the largest recorded mass extinction in Earth's history at the end of the Permian.

They suggest that volatiles released from a subducting slab infiltrated the overlying lithosphere prior to the eruptions. Released during the flood basalt eruptions, these volatiles would have contributed to climatic fluctuations and environmental degradation during the end-Permian crisis.
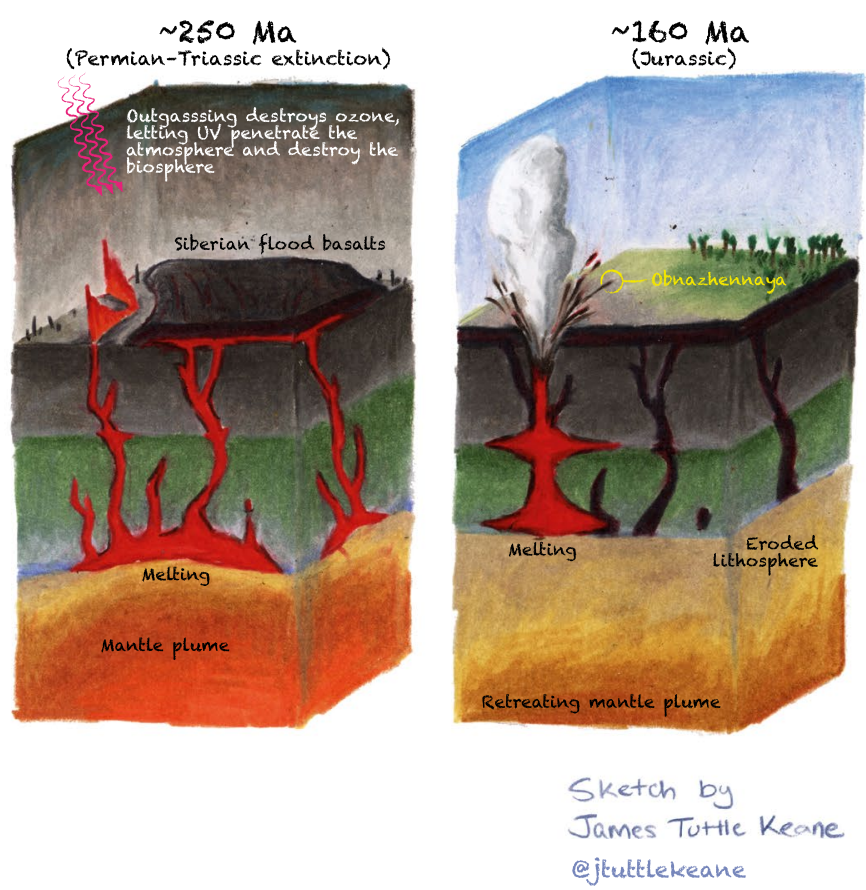

@jtuttlekeane 